\title{
Deoxygenation of liquid titanium with aluminum addition
}

\author{
Daisuke Matsuwaka $^{1}$, Fumiaki Kudo ${ }^{2}$, Hitoshi Ishida ${ }^{1}$, Tetsushi Deura ${ }^{3}$ \\ 1 Material Research Laboratory, Kobe Steel Ltd, Japan \\ 2 Material Solutions Division, Technology Unit, KOBELCO RESEARCH INSTITUTE, INC \\ 3 Mechanical Engineering Research Laboratory, Kobe Steel Ltd, Japan
}

\begin{abstract}
$\underline{\text { Abstract }}$
To realize radical cost reduction of titanium, a process is needed which can directly make use of low quality material such as scrap, $\mathrm{TiO}_{2}$ or titanium ore. In this work, a highly efficient process has been developed to produce low oxygen titanium alloy using aluminum to rapidly reduce oxygen during melting. In this experiment titanium was prepared including 0.8 mass $\%$ oxygen. This titanium and aluminum in the range of $0-60$ mass $\%$ was measured, mixed and melted by PAM (plasma arc melting) or ISM (induction skull melting). After melting, a small piece was taken and the aluminum and oxygen content was analyzed by ICP emission spectrometry and inert gas fusion-infrared absorption method respectively. A sample melted with $\mathrm{CaO}-\mathrm{CaF}_{2}$ flux was analyzed as well after flux was mechanically taken off. As aluminum content increased, oxygen content decreased. For example, when 61.9 mass $\%$ aluminum was added, the oxygen content decreased to 0.028 mass $\%$ and $\mathrm{Al}_{2} \mathrm{O}_{3}$ was observed in the cross-section of the sample after melting. This was produced when the aluminum content increased and the oxygen solubility decreased in the metal. Flux addition was also clearly effective for deoxygenation.
\end{abstract}

\section{Introduction}

Titanium and titanium-based alloys are used in several fields such as aerospace, chemical, power generation and seawater desalination plants due to their excellent physical and chemical properties, such as high specific strength and high corrosion resistance. For these reasons, the use of titanium is expected to increase in the future. However, because of its complicated production process and low yield, titanium is recognized as an "expensive material". For further expansion for both application and world wide markets, a groundbreaking process for cost reduction is awaited. 
Focusing on the titanium melting process, in general, titanium melting starts from sponge-titanium and other additional elements. To realize dramatic cost reduction, a low-grade material such as scrap or $\mathrm{TiO}_{2}$ must be used. When using such low-grade material, an increase in inpurities is inevitable and one of the major impurities is oxygen. Heretofore, a lot of research has been done to remove oxygen using solid state reaction[1-4] and liquid state reaction[5-9]. However, neither the proposed principle nor process has been applied to mass production so far due to the strong affinity between titanium and oxygen. On the other hand, considering the increase in titanim products and the status of titanium mineral resources in the future, development of an effective and resource saving deoxygenation process is an urgent requirement.

In this paper, a deoxygenation process via liquid titanium using aluminum which is a common alloying element is proposed.

\section{Materials and experiments}

In this study, titanium with high oxygen content was prepared using an arc melting furnace as a "starting material". The target oxygen content was 0.8 mass $\%$ and it was prepared by mixing $\mathrm{TiO}_{2}$ and grade $1 \mathrm{CP}$-Ti. Using this "starting material", titanium and aluminum in the range of $0-60 \mathrm{mass} \%$ was measured, mixed and melted by PAM (lasma $\underline{\text { Arc }}$ Melting) or ISM (induction $\underline{\text { Skull }} \underline{\text { Melting). As }}$ oxygen content in aluminum was negligibly low, oxygen was supplied only from "starting material". In some experiments, flux consisting of 20 mass $\% \mathrm{CaO}$ and 80 mass $\% \mathrm{CaF}_{2}$ which has a low melting point and quickly forms a liquid state to ensure a smooth reaction with liquid titanium alloy, was added to accelerate the refining effect. Melting was mainly done by PAM and the melting time was 0.9 ks for each. The sample shape was D60 x $20^{\mathrm{H}} \mathrm{mm}$ ellipsoidal and $\mathrm{D} 210 \times 250^{\mathrm{H}} \mathrm{mm}$ cylindrical, and the weight was approximately $120 \mathrm{~g}$ and $15 \mathrm{~kg}$ for PAM and ISM respectively.

After melting, a small piece was taken and aluminum and oxygen content was analyzed by ICP emission spectrometry and inert gas fusion-infrared absorption method respectively. The sample melted with $\mathrm{CaO}-\mathrm{CaF}_{2}$ flux was analyzed as well after the flux was mechanically taken off. Also, for practical study, a sample melted by ISM was solidified in a water cooled copper crucible and the flux was taken off. After the flux was taken off, CP-Ti was added to adjust the composition.

Grade $1 \mathrm{CP}$-Ti was an in-house product, $\mathrm{TiO}_{2}, \mathrm{CaO}, \mathrm{CaF}_{2}$ were purchased from a high purity materials supplier and aluminum was purchased from Nisshin specialty metals respectively. Melting was performed by PAM furnace at Nihon-tokusyukikai and by an in-house ISM furnace which is capable of $20 \mathrm{~kg}$ batch melting. 


\section{$\underline{\text { 3. Results }}$}

The oxygen and aluminum content after melting without flux addition is shown in Fig.1. It is obvious that with increasing aluminum content, oxygen content decreased, particularly when the aluminum content exceeded 40 mass $\%$.

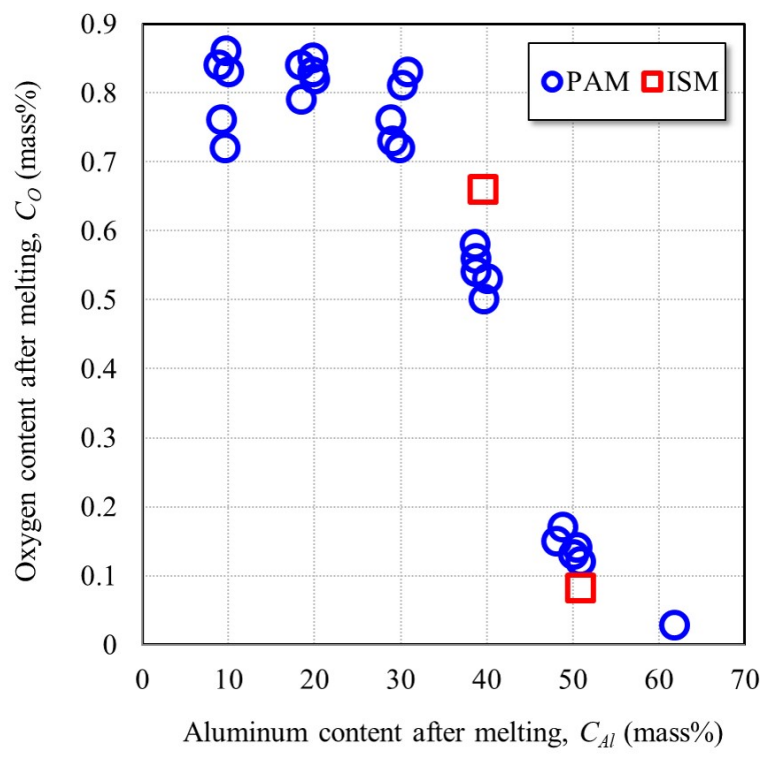

Fig.1 Oxygen and aluminum content after melting without flux addition

For example, when 61.9 mass\% aluminum was added, the oxygen content decreased to 0.028 mass $\%$. For further investigation, a cross section of a sample after melting was observed by an EPMA

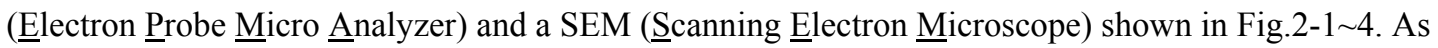
Fig.2-4 shows, $\mathrm{Al}_{2} \mathrm{O}_{3}$ was formed inside the sample when deoxygenation took place.

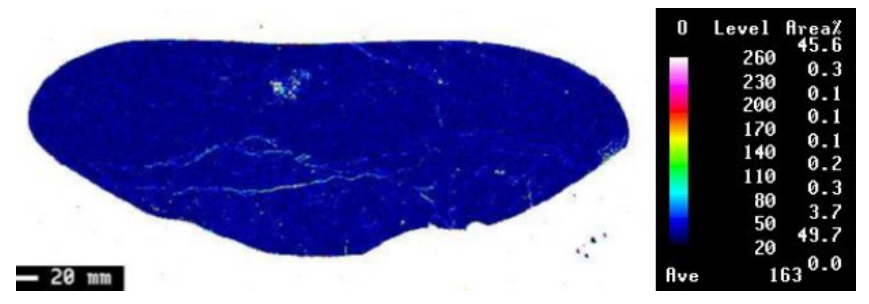

Fig.2-1 EPMA image for oxygen of Ti-30mass $\% \mathrm{Al}$ 
(PAM melted)

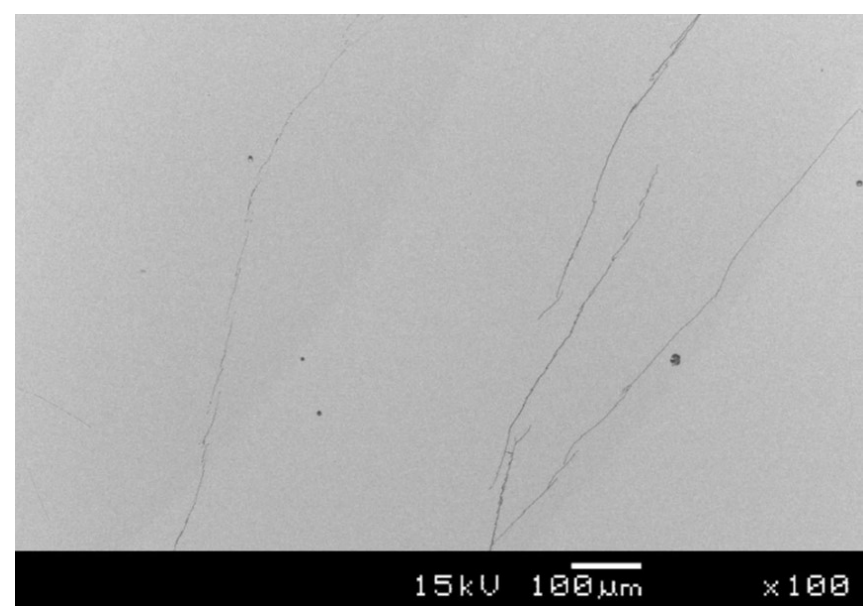

Fig.2-2 Back scattered image of Ti-30mass\%Al

(PAM melted)

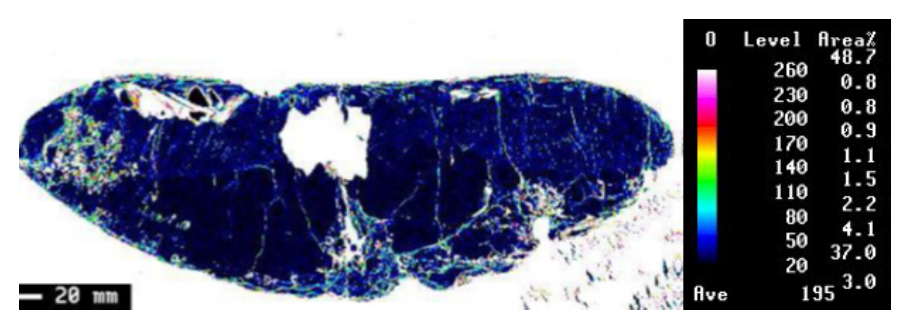

Fig.2-3 EPMA image of Ti-60mass\%Al

(PAM melted) 


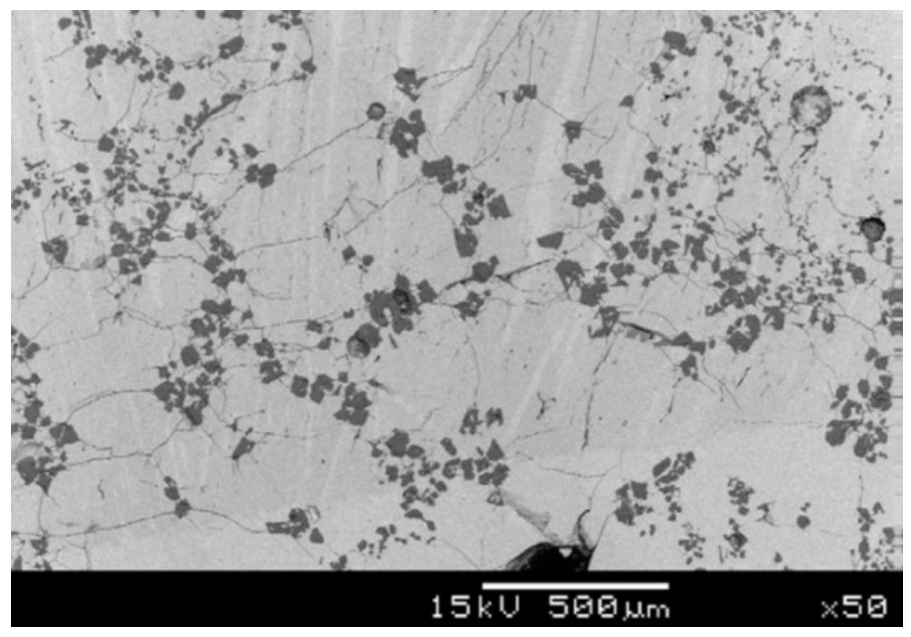

Fig.2-4 Back scattered image of Ti-60mass\%Al

(PAM melted)

After this study, another study to verify the deoxygenation acceleration was added. Fig.3 includes the oxygen and aluminum content after melting with flux addition. It can be seen that the oxygen content decreased compared to the result with the same aluminum content without flux addition.

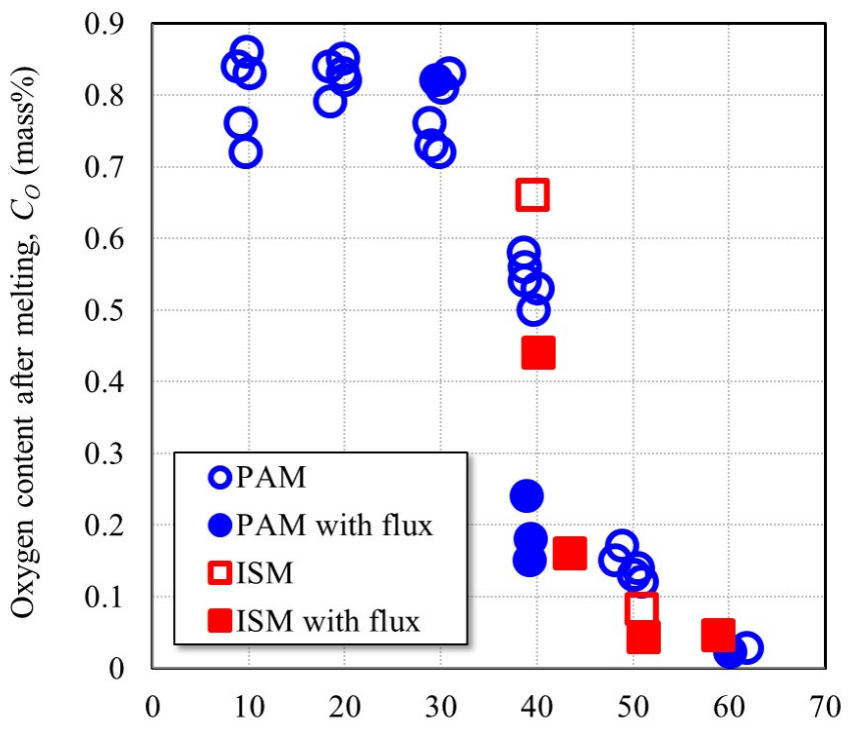

Aluminum content after melting, $C_{A l}(\operatorname{mass} \%)$ 
Fig.3 Oxygen and aluminum content after melting with flux addition

In addition, an investigation by EPMA was carried out in the same way as the previous study. A EPMA image of the sample cross section with flux addition is shown in Fig.4. Compared to Fig.2-4, neither $\mathrm{Al}_{2} \mathrm{O}_{3}$ nor engulfed flux were observed in the cross section with flux addition.

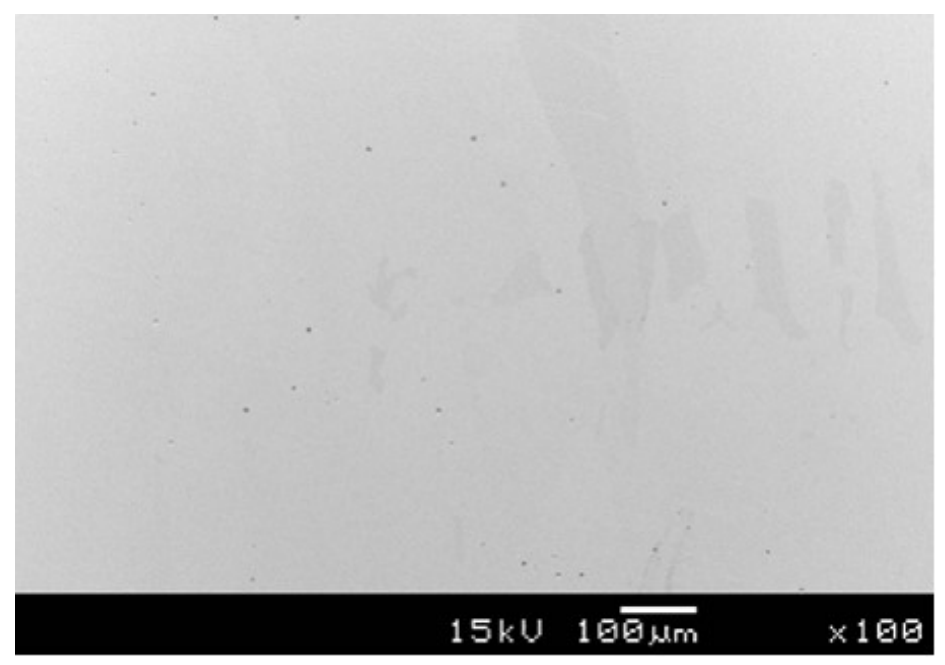

Fig.4 Back scattered image of Ti- $60 \mathrm{mass} \% \mathrm{Al}$ with flux addition

(PAM melted)

From these results, a practical study carried out using an ISM furnace. Fig.5 shows the ingot surface before flux was taken off. The ingot was covered with flux after solidification and was separated from the metal. Fig. 6 shows the oxygen and aluminum content variation after dilution by CP-Ti for composition control. The arrows in Fig.6 indicate the original composition before dilution. 


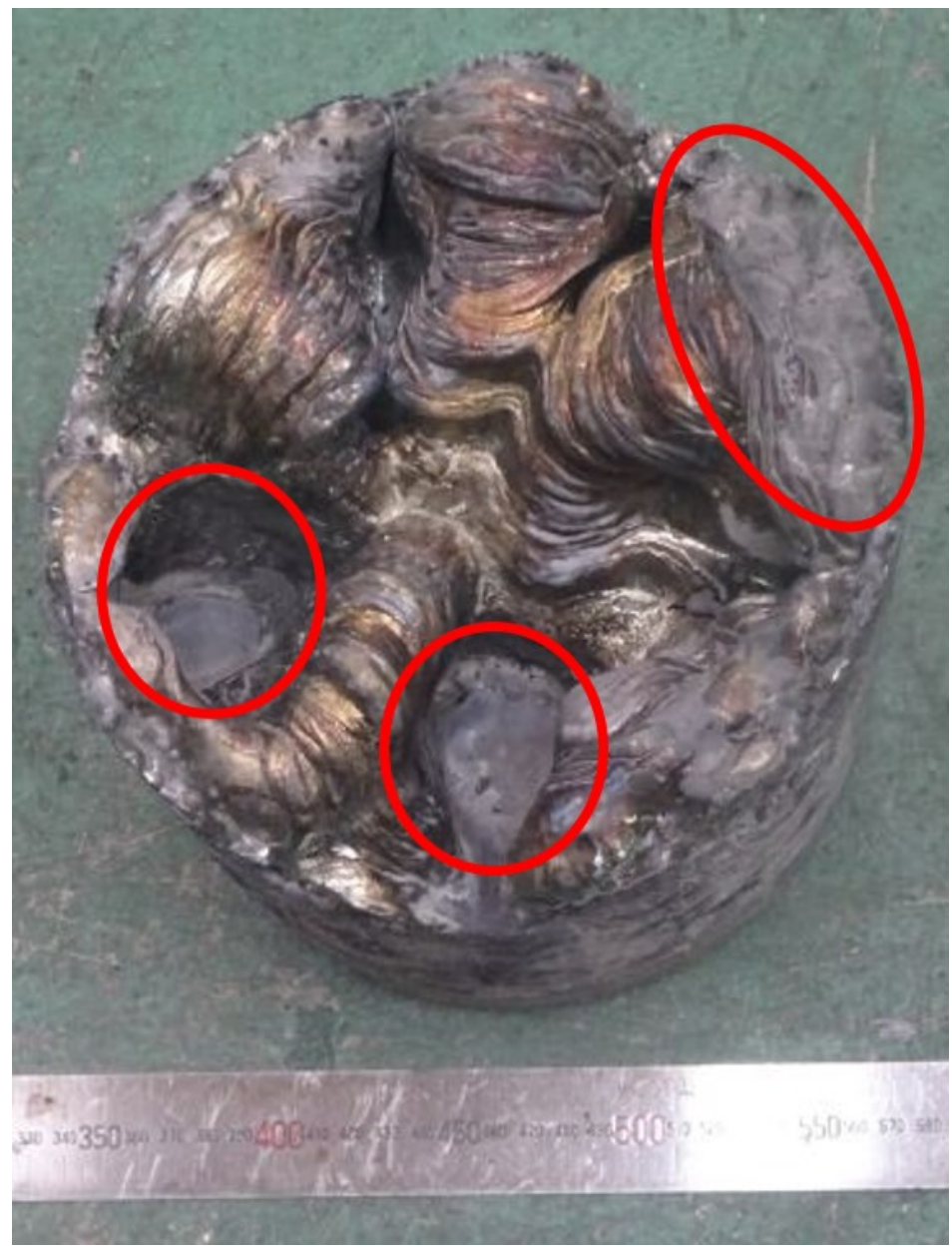




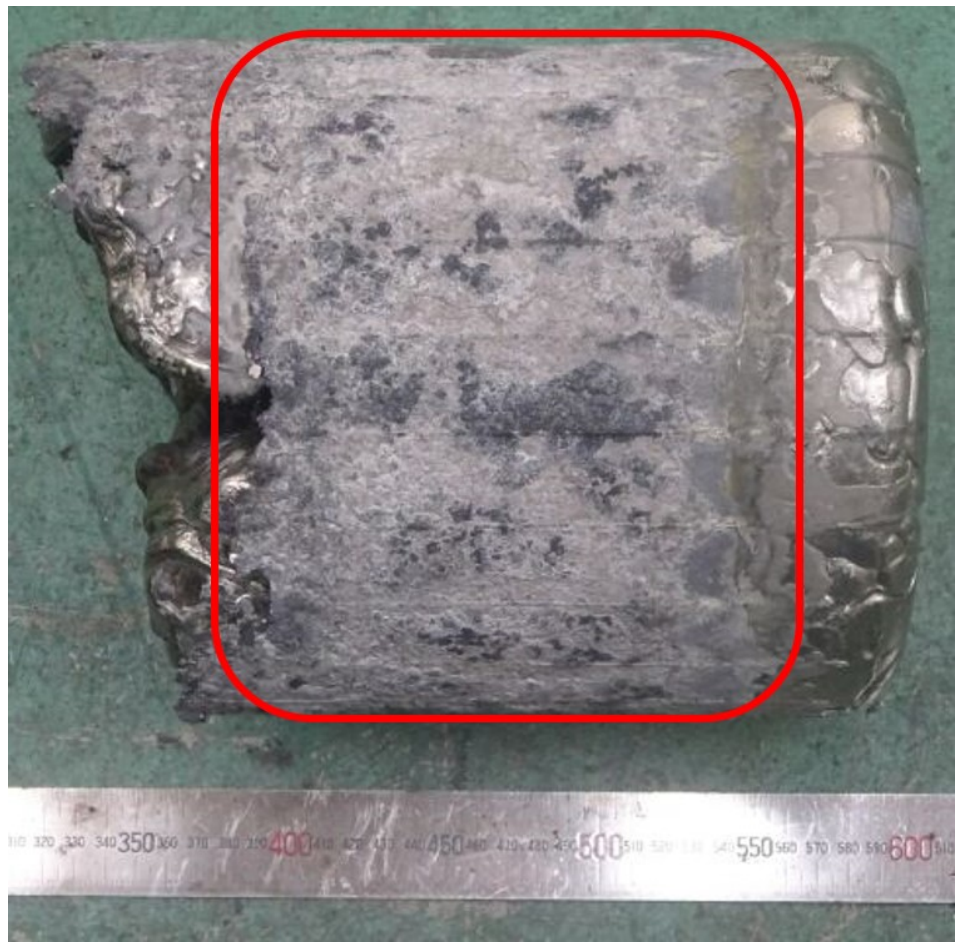

Fig.5 Ingot surface after solidification from top view (a) and side view (b)

(red area shows remaining flux on ingot surface) 


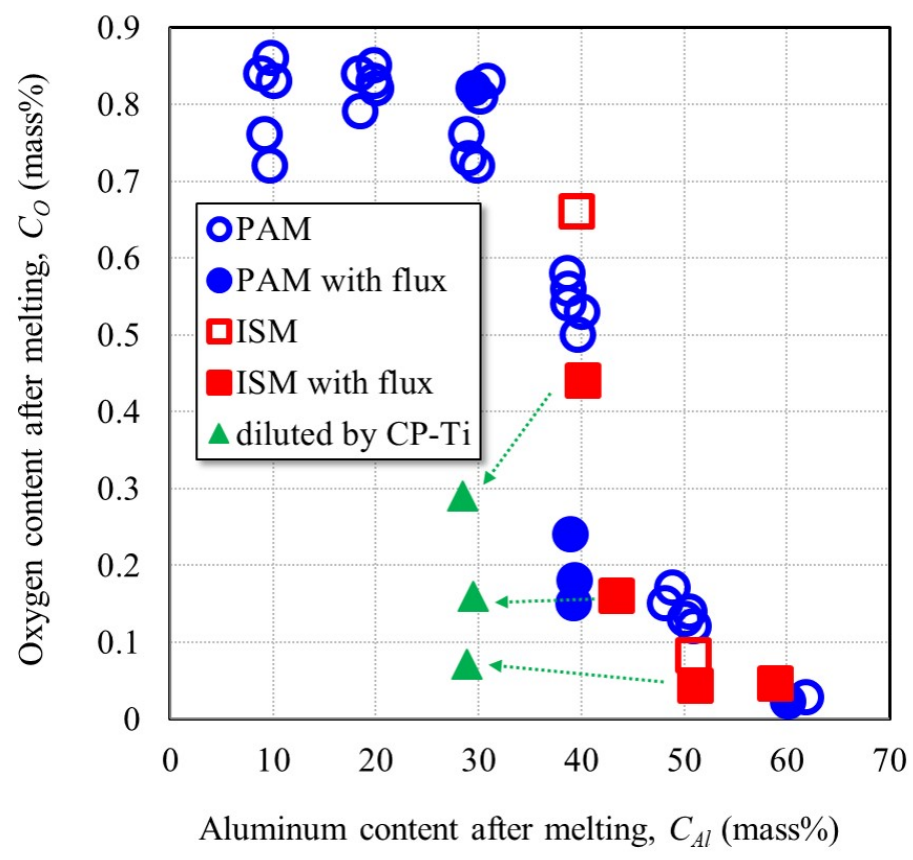

Fig.6 Oxygen and aluminum content after melting with flux addition

\section{Discussion}

From Fig.1 and Fig.2, deoxygenation is governed by equation (1) due to low solubility in TiAl especially for g-TiAl in solid state[10].

$$
\mathrm{Al}(\text { in } \operatorname{TiAl}(1))+\underline{\mathrm{O}}(\text { in } \operatorname{TiAl}(1))=\mathrm{Al}_{2} \mathrm{O}_{3}(\mathrm{~s})
$$

This low solubility in liquid state is also pointed out in the calculated phase diagram shown in Fig.7 and other articles[11]. As shown in Fig.7, the oxygen solubility in liquid Ti-Al decreases as the aluminum content increases. Oxygen solubility seem to decrease lower than 0.8 mass\% when aluminum content increase more than 40 mass \%. This correspond with the result shown in Fig.1,3. 


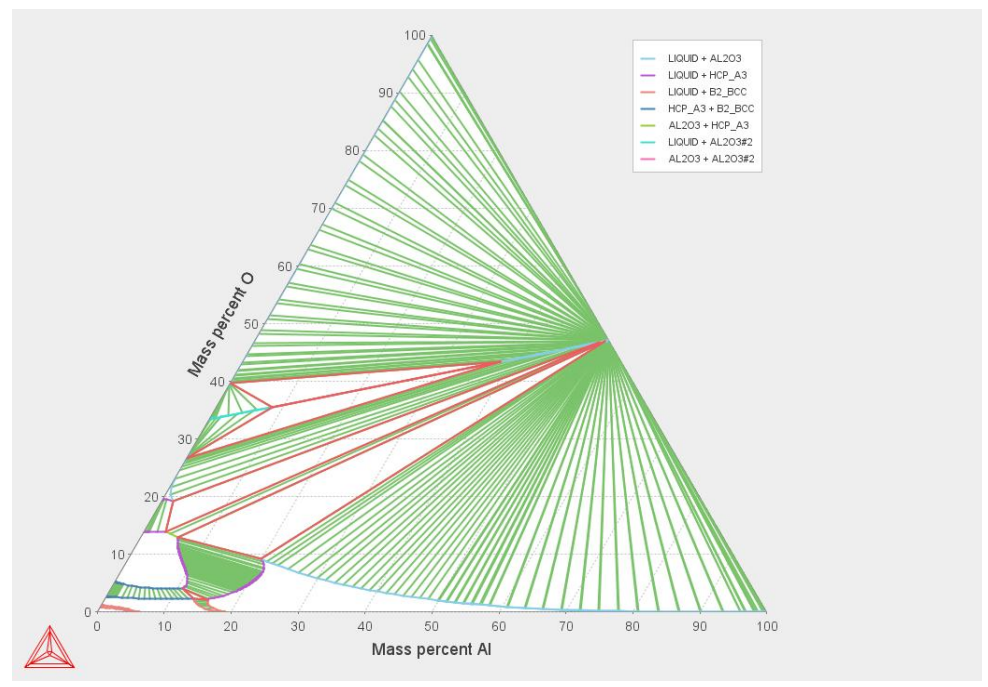

Fig.7 Calculated Ti-Al-O ternary phase diagram at $1973 \mathrm{~K}$

(Calculated by Thermo-Calc)

To accelerate the deoxygenation reaction, it is important to maintain the activity of the deoxidation product $\mathrm{Al}_{2} \mathrm{O}_{3}$ at a low level. After consideration of several solutions, using molten flux was decided on as the most practical method. As the desired properties for flux were a low melting point and high solubility of $\mathrm{Al}_{2} \mathrm{O}_{3}$, the $\mathrm{CaO}-\mathrm{CaF}_{2}$ system was chosen. From the $\mathrm{CaO}-\mathrm{CaF}_{2}-\mathrm{Al}_{2} \mathrm{O}_{3}$ ternary phase diagram, 20mass $\% \mathrm{CaO}-80$ mass $\% \mathrm{CaF}_{2}$ was selected to ensure a low melting point and high $\mathrm{Al}_{2} \mathrm{O}_{3}$ solubility for flux composition.

As a result, with flux addition, the oxygen content decreased (Fig.3) and the $\mathrm{Al}_{2} \mathrm{O}_{3}$ which formed inside the sample disappeared (Fig.4) although the aluminum content is the same in the sample shown in Fig.2-4 and Fig.4. This indicates that $\mathrm{Al}_{2} \mathrm{O}_{3}$ formed during melting and aluminum addition was absorbed into the flux and this reaction lowered the $\mathrm{Al}_{2} \mathrm{O}_{3}$ activity as expected. Moreover, as shown in Fig.4, engulfment of flux, at least in this research, during the melting process was not observed.

Unfortunately as there are no practical commercial titanium products which contain more than 50 mass\% aluminum, dilution by CP-Ti is necessary. Moreover, the aluminum content must be lowered, to approach 30 mass\%. In addition, the "flux skin" (shown in Fig.5) should be taken off to keep the oxygen content low even after dilution by CP-Ti for composition control, as shown in Fig.6. Otherwise, when aluminum content decreases by dilution, the absorbed $\mathrm{Al}_{2} \mathrm{O}_{3}$ returns from flux to metal and is decomposed to dissolved oxygen and aluminum. Due to this reaction, the total mass of oxygen in metal does not change and results in a regain of oxygen content. 


\section{Conclusion}

Deoxygenation of titanium was successfully achieved with aluminum addition. In particular, more than 50 mass \% aluminum addition is required to achieve an oxygen content of below 0.05 mass $\%$ which is a commercially valuable level. Also using this reaction, a deoxygenation process via a high aluminum content intermetallic compound was developed. This process has the potential to be adapted to all aluminum containing titanium alloys and consists of two stages. The first stage is "aluminum addition" to increase aluminum content and exclude oxygen from metal. The second stage is "dilution by CP-Ti" to achieve appropriate chemistry.

\section{Acknowledgements}

This research was based on results obtained from a project commissioned by New Energy and Industrial Technology Development Organization (NEDO).

\section{References}

[1] T. H. Okabe et al, ISIJ International, 77 (1991) 93-99

[2] R. L. Fisher et al, Titanium '92: science and technology, The Minerals, Metals \& Materials Society.,

3 (1993) 2265-2272

[3] G. Z. Chen et al, Metallurgical and Materials Transactions B, 32B (2001) 1041-1052

[4] J. M. Oh et al, Powder Metallurgy, 55 (2012) 402-404

[5] K. Sakamoto et al, ISIJ International, 32 (1992) 616-624

[6] T. Yahata et al, Metallurgical and Materials Transactions B , 24B (1993) 599-604

[7] Y. Su et al, International Journey of Hydrogen Energy, 34 (2009) 8958-8963

[8] K. Mimura et al, Materials Letters, 64 (2010) 411-414 
[9] J. M. Oh et al, International Journey of Hydrogen Energy, 41 (2016) 23033-23041

[10] A. Menand et al, Acta Materialia, 44 (1996) 4729-4737

[11] Y. Kobayashi et al, High Temperature Materials and Processes, 19 (2000) 211-218 